\title{
Improved method for the scalar control of induction motor drives
}

\author{
Andrew Smith, Shady Gadoue, Matthew Armstrong and John Finch \\ School of Electrical and Electronic Engineering, \\ Newcastle University, Newcastle upon Tyne, NE1 7RU \\ England, United Kingdom \\ E-mail: andrew.smith@,newcastle.ac.uk
}

\begin{abstract}
Many control schemes have been proposed for induction motors, which are in themselves highly complex nonlinear and sometimes internally unstable systems. One of the most accurate control schemes is encodered rotor flux orientated vector control. The advantages and disadvantages of this control are well known and several variations, or reduced vector schemes, have been proposed. This study introduces an improved encoderless scalar, or approximated vector, control method for induction machines which can be applied to general purpose applications that do not require the most precise control. The proposed method overcomes practical difficulties and is suitable for industrial applications. The slip compensated stator flux linkage oriented scheme proposed in this study does not require flux estimation or a speed sensor, only requiring nameplate data, stator current, and stator resistance measurement, which can easily be determined at start-up. Simulation and experimental investigations including field weakening operation and the effect of stator resistance variation demonstrate the improved performance of the new scheme compared to previous open loop $\mathrm{V} / \mathrm{Hz}$ and stator resistive compensated schemes especially at low rotor speeds.
\end{abstract}

\section{Nomenclature}

\begin{tabular}{|c|c|}
\hline$\omega_{r}$ & rotor speed $(\mathrm{rad} / \mathrm{s})$ \\
\hline$R_{S}, R_{r}$ & stator, rotor resistance \\
\hline $\bar{v}_{s}^{g}, \bar{i}_{s}^{g}, \bar{\psi}_{s}^{g}$ & $\begin{array}{l}\text { stator voltage, current, and flux linkage in } \\
\text { general reference frame }\end{array}$ \\
\hline $\bar{v}_{s}^{e}, \bar{i}_{s}^{e}, \bar{\psi}_{s}^{e}$ & $\begin{array}{l}\text { stator voltage, current, and flux linkage in } \\
\text { excitation (synchronously rotating) } \\
\text { reference frame }\end{array}$ \\
\hline$L_{m}, L_{l s}, L_{l r}$ & $\begin{array}{l}\text { mutual, stator leakage, \& rotor leakage } \\
\text { inductance }\end{array}$ \\
\hline$f_{e}, \omega_{e}$ & excitation frequencies $(\mathrm{Hz}) /(\mathrm{rad} / \mathrm{s})$ \\
\hline$v_{d s}^{S}, v_{q s}^{s}, i_{d s}^{s}, i_{q s}^{S}$ & $\begin{array}{l}\text { direct and quadrature components of the } \\
\text { stator voltage and current in the stator } \\
\text { reference frame }\end{array}$ \\
\hline$v_{d s}^{e}, v_{q s}^{e}, i_{d s}^{e}, i_{q s}^{e}$ & $\begin{array}{l}\text { direct and quadrature components of the } \\
\text { stator voltage and current in the excitation } \\
\text { (synchronously rotating) reference frame }\end{array}$ \\
\hline$\psi_{d s}^{e}$ & $\begin{array}{l}\text { direct axis stator flux linkage in excitation } \\
\text { reference frame }\end{array}$ \\
\hline$v_{S_{-} \text {rated }}$ & rated stator voltage, stator current, and stator \\
\hline$I_{s_{-} \text {rated }}, \omega_{e_{-} \text {rated }}$ & frequency $(\mathrm{rad} / \mathrm{s})$ \\
\hline$p p$ & number pole pairs \\
\hline$\omega_{\text {comp }}$ & slip compensation frequency (rad/s) \\
\hline$E_{s}, E_{m}$ & $\begin{array}{l}\text { stator back electromotive force, magnetising } \\
\text { back electromotive force }\end{array}$ \\
\hline$s, s_{\text {rated }}$ & slip, rated slip \\
\hline Superscript "*" & indicates demanded value \\
\hline
\end{tabular}

\section{Introduction}

In induction machines, torque and slip are intrinsically linked as each is dependent on the other. High performance control throughout the rotor speed range is possible with variable frequency inverters and encodered rotor flux linkage oriented vector control schemes, the foundations of which were established many years ago. However, this comes with the expense of the hardware needed including an encoder and more complicated control algorithms. Since then only limited work on scalar schemes has been reported even though it is still widely used. However, the use of adaptive control mechanisms such as fuzzy logic is still occasionally published $[1,2]$. For less demanding applications economical speed control can be achieved using the inherent principles of the machine as given in (1).

$$
\omega_{r}=\frac{2 \pi f_{e}}{p p}(1-s)
$$

The well-known $\mathrm{V} / \mathrm{Hz}$ method, where the $\mathrm{V} / \mathrm{Hz}$ ratio is kept constant to maintain the stator flux linkage, is a simple example of scalar control. Low-speed operation using this method is problematic due to the stator resistance voltage drop and the slip needed to produce torque. Hence many boost methods, some of which involve decoupling the control components, have been proposed [3, 4]. In comparison to these scalar methods where only the magnitude of the applied values are altered, vector or field oriented methods (such as stator, air-gap, or 
rotor flux) vary both the magnitude and phase of the variables. This allows better dynamic performance which makes vector control based schemes predominant for high performance drives, although with varying parameter dependencies. Rotor flux oriented schemes, especially the commonly used indirect method, are dependent on the $L_{r}$ and $R_{r}$ parameters, whereas stator oriented schemes are affected mainly by $R_{s}$. Direct torque control (DTC) is also increasingly used in drive applications due to its ability to quickly change the electrical torque and stator flux without coordinate transforms or PI control. However, this scheme still has a coupling effect between the rotor speed and stator flux [5], plus well-known integration issues that also affect rotor speed estimation schemes and $R_{s}$ dependancy to estimate these parameters. Many authors have discussed the variations and general principles of scalar and vector schemes $[6,7]$; others $[8,9]$ give an overview of current and future industrial drives. Buyukdegirmenci and Krein [10] discussed the maximum torque capabilities of an augmented $\mathrm{V} / \mathrm{Hz}$, rotor flux oriented, and DTC schemes, whereas a comparison between vector control and DTC in electric vehicle applications is shown in [11]. To reduce cost and increase the robustness and reliability of the drive system, encoderless control schemes such as model reference adaptive systems (MRAS), extended Kalman filters (EKF), or signal injection have become a common research area [12-14]. However, knowledge of machine parameters, and increased processing power to implement the more sophisticated control algorithms including online parameter identification are needed. For example, full and reduced order observers have been used to estimate $R_{S}$ and $R_{r}$ and hence accurately control the machine [15-17]. In many applications the high performance and cost associated with an indirect rotor flux vector method is unnecessary and simple scalar based schemes are often used. However, even though the system complexity is reduced, there is an accompanying penalty of a decrease in the dynamic response to both rotor speed and load torque demands. These inherent shortcomings can be minimised with schemes that look at compensating the stator resistance voltage drop and the speed variation due to load application (slip compensation).

In low power, small scale systems, the removal of the encoder is often important for both cost and reliability reasons. However, in higher power systems other considerations take over. For example, in certain applications, the encoder cost may be small compared to that of the cables. Hence, a compromise has to be sought between complexity, cost, processing power and accuracy of a control method. If accurate dynamic control is required, the control scheme will usually be more expensive and complex (vector based), but by making specific assumptions it is possible to significantly reduce the complexity without unduly compromising the performance [3]. This paper introduces a slip compensated industrially applicable scalar control method capable of improved performance in both transient and steady state and has a much simpler implementation than other proposed solutions [4, 18]. This schemes simplicity and compensative behaviour lend it towards a variety of applications; primarily lower power schemes such as fans and compressors that do not require the full dynamic performance of a vector based scheme. The technical, economic, and cost effectiveness of such applications with variable speed drives are shown in [19, 20]. Another potential application [21], explains a fault tolerant scheme for electric vehicles which adaptively changes the control (including sensorless scalar) in the event of sensor loss to attain the best performance.

The proposed method is realised using an open loop, stator flux oriented concept. Utilising vector control principles and name plate data, the slip is compensated by a feed forward scheme based on a linear $i_{q s}^{e}$ relationship.

Simulations and experimental tests are presented which validate the improved performance of the proposed control scheme. Results are compared to classic $\mathrm{V} / \mathrm{Hz}$, indirect rotor flux oriented vector control, and the technique described in [3].

\section{Scalar control schemes}

$\mathrm{V} / \mathrm{Hz}$ control is well known, using a feed forward method in an attempt to maintain the stator flux linkage constant up to rated speed. This control is very simple to implement but the inherent coupling of the induction machine variables give a sluggish dynamic response, but this is a fair trade-off in applications such as fans or pumps where speed feedback is not always required and limited dynamic performance is acceptable. The stability of an open loop induction machine drive is discussed in [22]; [23] looks at fault tolerant operation of scalar and vector methods, whereas energy saving strategies for scalar schemes are proposed in [24].

At higher rotor speeds the stator resistance voltage drop is negligible and can be ignored. However, as the rotor speed and excitation frequency reduce this drop can have a 
significant effect on the machine operation. Many solutions have been proposed for voltage boost at low speeds to compensate for this drop. Commonly a fixed value up to $25 \%$ of the rated stator voltage [25], or a fixed value equivalent to the full load $I_{S_{-} \text {rated }} R_{S}$ are used. However, these can cause problems as the values will only be correct for a single operating point, leading to over excitation of the machine with no load. The fixed values also mean that the voltage limit will be reached before the rated frequency. An alternative is to alter the slope of the boost so that at rated frequency no boost is applied; modern industrial control systems vary the boost depending on operating conditions.

More complicated but improved compensation methods [3, 18] use transformation methods as used in vector control, Munoz-Garcia et al [18] modify the stator voltage applied (2) based on the phasor diagram.

$$
\begin{gathered}
V_{S}=I_{S} R_{S} \cos \phi \\
+\sqrt{\left(\frac{E_{S_{s} \text { rated }} f_{e}^{*}}{f_{e_{-} \text {rated }}}\right)^{2}-\left(I_{s} R_{s}\right)^{2}(\sin \phi)^{2}}
\end{gathered}
$$

This method is now widely applied [4, 26-29] although [4] states it is too complicated. In [30] the authors discuss four different boost methods with both current feedback compensation and the vectorial method adopted in [18]. At low speeds the air gap flux linkage is approximately equal to the stator flux linkage as the leakage term is negligible. However, in this paper, a method, taking into account both the stator resistance and reactive components, is introduced with the aim of keeping the air gap flux linkage constant as given by (3).

$$
\begin{gathered}
V_{s}=\frac{\omega_{e} L_{l s} I_{s}}{\sin \phi}+\left(I_{s} R_{s}-\frac{\omega_{e} L_{l s} I_{s}}{\sin \phi} \cos \phi\right) \cos \phi \\
+\sqrt{\left(\frac{E_{m_{-} \text {rated }} f_{e}^{*}}{f_{e_{-} \text {rated }}}\right)^{2}-\left(I_{s} R_{s}-\frac{\omega_{e} L_{l s} I_{s}}{\sin \phi} \cos \phi\right)^{2}(\sin \phi)^{2}}
\end{gathered}
$$

Tsuji et al [31] introduce a stator leakage impedance compensation scheme. This method estimates the stator voltage and compares it with a frequency dependant term for the air gap flux; the error generates the stator voltage demand.

Much work discusses slip compensation; Rubin et al [32] investigate ten published slip estimation techniques under field oriented conditions with only two showing satisfactory operation. Moreover, computationally intensive methods are employed in $[33,34]$ to estimate the slip using spectral analysis of the stator current and the equivalent circuit input impedance equation, respectively. Binying et al [35] investigate a scalar scheme using a phase-locked loop (PLL) tracking the rotor slot harmonics for rotor speed estimation.

Other schemes estimate the stator flux, using this to help compensate both the $R_{S}$ effect and for slip compensation. [36-38] compare the estimated stator flux to the desired to control the direct axis voltage. In [39], the stator flux is used to estimate the stator back emf for the voltage boost and slip frequency, whereas Hui et al [4] use it to estimate the rotor flux and hence the electromagnetic torque and slip frequency as shown in (4) and (5). In [27, 39] the slip frequency is calculated using (6), and $[37,38]$ calculate the excitation frequency using (7), combining this with a linear approximation of the torque / slip relationship (8). The torque is calculated from the estimated stator flux and uses (9) to obtain the rotor speed; Koga et al [40] also use this linear relationship. The constant term shown in (8) is rarely mentioned in papers. [18, 29] both calculate the air gap power, Munoz-Garcia et al [18] uses (10a/10b) based around a simplified equation relating torque and slip, an alternative torque equation and the air gap power, whereas Pongpant and Po-ngam [29] use it to estimate the machine torque before (8). In [26] the torque is estimated using (11) and the same linear slip frequency / torque relationship is then used (8). For slip compensation [31, 41] use versions of (12). Yong et al [37] also shows another equation (13) that could be used in the stator flux reference frame; the parameter dependency shown in some of these equations mean accurate values are needed for precise control. Throughout these schemes many integration methods, including those shown in [42], are presented.

$$
\begin{gathered}
T_{e}=\frac{3}{2} p p\left(\psi_{d s}^{s} i_{q s}^{s}-\psi_{q s}^{s} i_{d s}^{s}\right) \\
\omega_{\text {slip }}=\frac{T_{e} R_{r}}{p p L_{m}^{2} i_{d s}{ }^{2}} \\
\omega_{\text {slip }}=\frac{L_{m}^{2}}{L_{r}^{2}} \frac{R_{r} \bar{\psi}_{s}^{s} \otimes \bar{l}_{s}^{s}}{\left(\bar{\psi}_{s}^{s}-\sigma L_{s} \bar{l}_{s}^{s}\right) \circ\left(\bar{\psi}_{s}^{s}-\sigma L_{s} \bar{l}_{s}^{s}\right)}
\end{gathered}
$$

Where $\otimes$ and $\circ$ indictate the cross product and inner product respectively.

$$
\begin{gathered}
\omega_{e}=\frac{\left(v_{q s}^{s}-i_{q s}^{s} R_{s}\right) \psi_{d s}^{s}-\left(v_{d s}^{s}-i_{d s}^{s} R_{s}\right) \psi_{q s}^{s}}{\psi_{d s}^{s}+\psi_{q s}^{{ }^{2}}} \\
\omega_{\text {slip }}=K T_{e}, K=\frac{\omega_{\text {slip_rated }}}{T_{e_{-} \text {rated }}} \\
\omega_{r}=\omega_{e}-\omega_{\text {slip }}
\end{gathered}
$$




$$
\begin{gathered}
\frac{1}{2-A P_{\text {gap }}}\left(\sqrt{\left(f_{r}^{*}\right)^{2}+\frac{K s_{\text {lin }}}{2 K_{o}} P_{\text {gap }}-B P_{\text {gap }}^{2}}-f_{r}^{*}\right) \\
A=\left(\frac{p}{4 \pi K K_{o} T_{\text {rated }} S_{\text {rated }} f_{\text {rated }}}\right), \\
B=\left(\frac{p}{4 \pi K_{o} T_{\text {rated }}}\right)^{2}, s_{\text {lin }}=\left(\frac{p}{\pi}\right) \frac{s_{\text {rated }} f_{\text {rated }}}{T_{\text {rated }}} \\
T_{e}=\frac{3}{2} \frac{p p}{2} \frac{v_{q s}^{e} i_{q s}^{e}-2 R_{s} I_{s}^{2}}{\omega_{e}^{*}} \\
f_{\text {slip }}=\frac{R_{r}}{2 \pi L_{r}} \frac{i_{q s}^{e}}{i_{d s}^{e}} \\
\omega_{\text {slip }}=\frac{\left(1+\sigma T_{r} p\right) L_{s} i_{q s}^{e}}{T_{r}\left(\psi_{d s}^{e}-\sigma L_{s} i_{d s}^{e}\right)}
\end{gathered}
$$

An alternative control scheme is natural field orientation, which is related to, and can be regarded as, a simplified stator flux oriented method. Instead of estimating the stator flux with its inherent integration issues it is assumed to be at its reference value, which is used to estimate the angular velocity of the stator flux vector and hence position. Mirzaeva and Betz [43] give an introduction to the scheme and comparison to stator flux orientation, whereas full stability analysis is provided in [44]. Alternative simple control schemes for permanent magnet machines include [45, 46]. Ancuti et al [45] discuss sensorless $\mathrm{V} / \mathrm{Hz}$ control of a 20,000rpm permanent magnet synchronous machine. Two control loops are implemented to control the amplitude of the applied voltage and its phase based on the internal reactive power. The scheme avoids closed-loop control of both the stator current and rotor speed and the use of Park transformations. Moldovan et al [46] also avoid the use of the control loops and transformations, simulating three different $\mathrm{V} / \mathrm{Hz}$ based control strategies which attempt to compensate the applied voltage and phase. All of the schemes are more computationally intensive than Ancuti et al's scheme [45]. In addition there is the requirement for estimating the stator flux components and increased parameter dependency through the use of inductive terms.

The more complicated concept shown in [3] uses decoupled $d q$ components and the stator flux linkage orientated control to try and overcome difficulties in establishing the boost voltage to satisfy diverse operating conditions. Modelling of induction machines using space vectors is widely described and the stator voltage vector, expressed in a general reference frame is given as:

$$
\bar{v}_{s}^{g}=\bar{i}_{s}^{g} R_{s}+\frac{d \bar{\psi}_{s}^{g}}{d t}+j \omega_{g} \bar{\psi}_{s}^{g}
$$

Using the stator flux linkage orientated control concept which rotates with the excitation frequency (14) can be expressed as (15):

$$
\bar{v}_{s}^{e}=\bar{i}_{s}^{e} R_{s}+\frac{d \bar{\psi}_{s}^{e}}{d t}+j \omega_{e} \bar{\psi}_{s}^{e}
$$

The reference frame associated with (15) is aligned to the direct axis (i.e. the quadrature component is zero) and the steady state orthogonal components are:

$$
\begin{gathered}
v_{d s}^{e}=i_{d s}^{e} R_{s} \\
v_{q s}^{e}=i_{q s}^{e} R_{s}+\omega_{e} \psi_{d s}^{e}{ }^{*}
\end{gathered}
$$

The user sets the value of $\psi_{d s}^{e}{ }^{*}$ and $\omega_{e}$ (via $\omega_{r}^{*}$ ), with $\theta_{e}$ calculated from the integral of $\omega_{e}$. For stability the value of $R_{S}$ used in the controller must be less than the actual value; in [3] the value $\left(\tilde{R}_{S}\right)$ is $80 \%$ of the actual $R_{S}$.

This method gives good results and is much simpler than a rotor flux orientated scheme. However, this open loop control scheme has some significant drawbacks:

- The first problem is the user must set the value of $\psi_{d s}^{e}{ }^{*}$. This is unattractive in an industrial application since an ill-advised setting (by an inexperienced user) could yield unacceptable behaviour.

- Secondly, it is not apparent how it can be easily used in the field weakening region. Equation (16) shows that as $\omega_{r}^{*}$ and hence $\omega_{e}$ increases; $v_{q s}^{e}$ continues to increase even after the rated stator voltage is reached. Hence there is no clear mechanism to transfer the system from the constant torque to the constant power region in this very basic version of the scheme.

- The third and biggest problem is its behaviour in the presence of loads. In this simple open loop scheme there is no compensation of any load dependant rotor speed drops.

- A fourth problem, is that the control scheme depends upon the choice of $\tilde{R}_{s}$ for stability especially at low $\omega_{r}^{*}$. Altering this parameter influences the system stability and a new characteristic response is observed. With the addition of an $R_{S}$ estimator this problem can easily be overcome.

- A fifth problem is when $\omega_{r}^{*}=0, v_{s}^{e}=0$. From (16), $v_{d s}^{e}$ depends on the measured $i_{d s}^{e}$ while $v_{q s}^{e}$ depends on the measured $i_{q s}^{e}$ and $\omega_{e}$. Therefore operation around and through this region is problematic. 


\section{Proposed method}

Ideally, a new control scheme should solve the problems discussed, be much simpler than rotor flux orientated vector control, and still not require an encoder. The scheme presented here uses the stator flux linkage oriented method similar to those shown in $[3,18]$ including Park and Clarke transformations used for vector control, the overall schematic block diagram is shown in Fig. 1.

In this scheme a fixed $d$ axis voltage term is used (17), unlike $[3,18]$ where it is controlled by the feedback current, this overcomes the fifth problem mentioned.

$$
v_{d s}^{e}=I_{s_{\text {rrated }}} R_{s}
$$

The $\omega_{e} \psi_{d s}^{e *}$ term in (16) which causes the first and second problems is removed using the conditional expression (18). Technically, as shown in (2), this should be the rated value of $E_{s}$ for constant flux, however, since resistance compensation is taken into account this is an acceptable trade-off for the simplicity and use of nameplate data.

$$
v_{\text {basic }}=\left\{\begin{array}{ccc}
\frac{v_{s_{-} \text {rated }}}{\omega_{e_{-} \text {rated }}} \omega_{e} & \text { if } & \omega_{e} \leq \omega_{e_{-} \text {rated }} \\
v_{s_{-} \text {rated }} & \text { if } & \omega_{e}>\omega_{e_{-} \text {rated }}
\end{array}\right.
$$

Hence, $v_{q s}^{e}$ is given by:

$$
v_{q S}^{e}=i_{q S}^{e} R_{S}+v_{\text {basic }}
$$

These equations aim to maintain the stator flux linkage, but slip compensation is still needed to overcome the load dependant rotor speed drop. In the stator flux linkage reference frame the $d$-axis is aligned with the stator flux linkage while the $q$-axis current controls the torque, and in this frame the torque can be given as (20):

$$
T_{e}=K \psi_{d s}^{e} i_{q s}^{e}
$$

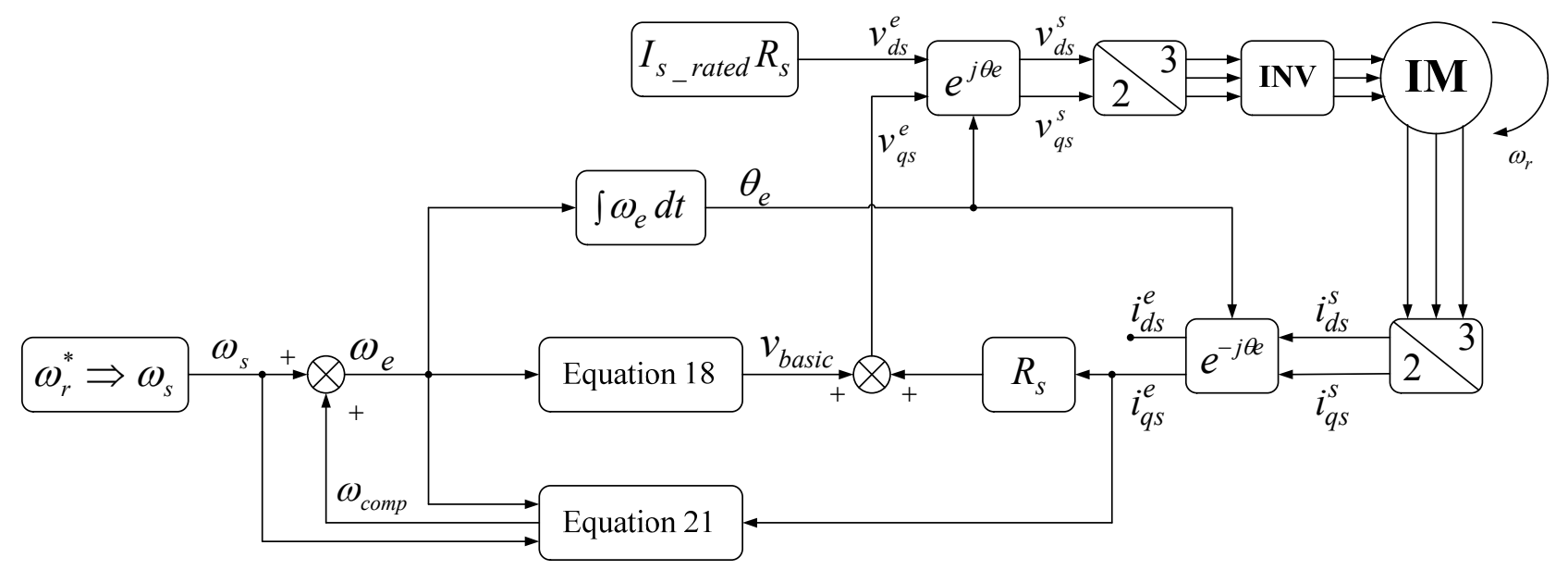

Fig. 1: Proposed scheme block diagram
Unlike the equations shown in (4) through (13) a much simpler calculation is possible to estimate the torque and hence slip frequency. Since the stator flux linkage is constant below rated speed the torque developed is dependent on the slip frequency and proportional to the $q$ axis current. Therefore a linear torque / slip relationship similar to (8) can be given as (21). In the constant torque operating region the torque and slip frequency are related; therefore, for variable speed operation for the same torque the same slip frequency must occur, the slip alters as $\omega_{e}$ varies but the slip frequency term remains constant. However, in the constant power field weakening region the slip frequency increases with $\omega_{e}$. The conditional expression relating these is also shown in (21), and using them to continually modify $\omega_{e}$ allows a value of $\omega_{r}$ close to that demanded to be achieved as the load varies. For simplicity, the influence of the rotor time constant on the slip frequency is ignored, thus eliminating the need for $R_{r}$ and $L_{r}$ estimation and adaptation.

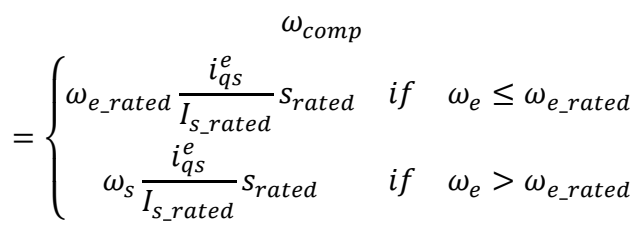

For $\mathrm{V} / \mathrm{Hz}$ and the scheme shown in [3] $\omega_{e}$ is calculated using (22), while for this proposed scheme it is given by (23):

$$
\begin{aligned}
& \omega_{e}=\omega_{s}=\omega_{r}^{*} p p \\
& \omega_{e}=\omega_{s}+\omega_{\text {comp }}
\end{aligned}
$$

For convenience $I_{s_{\text {_rated }}}$ is applied. This is found to give acceptable compensation and is also normally on the machines nameplate. Additional tuning of this value can further minimise possible error. 
Table 1: Experimental comparison of the schemes features. Overshoot settling to within $\pm 2 \%$, vector control results depend on control loop tuning

\begin{tabular}{|c|c|c|c|c|}
\hline & $\mathrm{V} / \mathrm{Hz}$ & $\begin{array}{l}\text { Stator resistance } \\
\text { compensation [3] }\end{array}$ & Proposed & $\begin{array}{l}\text { Indirect rotor flux } \\
\text { oriented vector control }\end{array}$ \\
\hline $\begin{array}{l}\text { overall execution time } \\
\text { (compared to } \mathrm{V} / \mathrm{Hz} \text { ) }\end{array}$ & 1 & 1.1 & 1.15 & 1.57 \\
\hline feedback loops & none & stator current & stator current & $\begin{array}{l}\text { stator current, rotor } \\
\text { speed }\end{array}$ \\
\hline low $\omega_{r}^{*} 25 \%$ load operation & $\begin{array}{c}\text { no (fails at } 6.28 \\
\mathrm{rad} / \mathrm{s})\end{array}$ & no (fails at $6.28 \mathrm{rad} / \mathrm{s}$ ) & yes (small offset) & yes \\
\hline encoderless operation & yes & yes & yes & $\begin{array}{l}\text { with a speed estimation } \\
\text { scheme. }\end{array}$ \\
\hline $\begin{array}{l}\text { field weakening operation } \\
\text { feasible }\end{array}$ & yes & not self-explanatory & yes & yes \\
\hline parameter sensitivity & N/A & $R_{S}$ & $R_{S}$ & $R_{s}, R_{r}, L_{m}, L_{l s}, L_{l r}$ \\
\hline start-up time (Fig. 2) & $70 \mathrm{~ms}$ & $200 \mathrm{~ms}$ & $30 \mathrm{~ms}$ & $23 \mathrm{~ms}$ \\
\hline $\begin{array}{l}\text { overshoot } \% \text { / settling time (Fig. } \\
\text { 2) }\end{array}$ & $3.15 \% / 0.857 \mathrm{~s}$ & $3.97 \% / 1.39 \mathrm{~s}$ & $3.75 \% / 0.842 \mathrm{~s}$ & $5.2 \% / 0.693 \mathrm{~s}$ \\
\hline $\begin{array}{l}\text { load torque impacts \% error } \\
\text { (Fig. 3) }\end{array}$ & $12.4 \%$ & $13.4 \%$ & $1.02 \%$ & $0 \%$ \\
\hline
\end{tabular}

Table 2: Four pole, $7.5 \mathrm{~kW}, 415 \mathrm{~V}, 50 \mathrm{~Hz}$, delta connected induction machine

\begin{tabular}{cc}
\hline Quantity & Value \\
\hline rated slip & 0.0384 \\
Per phase star equivalent parameters & \\
$R_{S}$ & $0.7767 \Omega$ \\
$R_{r}$ & $0.703 \Omega$ \\
$L_{m}$ & $103.22 \mathrm{mH}$ \\
$L_{l s}, L_{l r}$ & $4.51 \mathrm{mH}$ \\
\hline
\end{tabular}

\section{Experimental results}

For comparison and validation both simulation and practical testing were carried out, and a summary and comparison of the schemes features are shown in Table 1. Testing was based around a $7.5 \mathrm{~kW}, 415 \mathrm{~V}, 50 \mathrm{~Hz}$ delta connected induction machine (parameters are given in Table 2) and controlled by a dSpace DS1103 prototyping system. The control scheme runs at $15 \mathrm{kHz}$ with a sinusoidal pulse width modulation (PWM) switching strategy, limiting $\omega_{e}$ to $272 \mathrm{rad} / \mathrm{s}$ and $\omega_{r} \approx 136 \mathrm{rad} / \mathrm{s}$ (1298 rpm), before entering constant power field weakening. During testing, the machine slew rate was limited to $26.2 \mathrm{rad} / \mathrm{s}^{2}$.

To validate the improvement comparative tests based around those discussed in [47] were carried out and examples of the results, showing good correlation are shown in Figs. 2-5.

Where possible, high and low rotor speed capabilities of the schemes are compared; stepped responses from 15.7 $\mathrm{rad} / \mathrm{s}$ to 0 and back to $15.7 \mathrm{rad} / \mathrm{s}$ with $3.14 \mathrm{rad} / \mathrm{s}$ steps lasting 1 second and similar stepped responses going from 15.7 to $-15.7 \mathrm{rad} / \mathrm{s}$ are shown, whereas the start-up characteristics from $\omega_{r}^{*}=0$ (problem 5) and the responses of the schemes to load torque impacts are analysed (problem 3). High rotor speed tests including the transition from the constant torque into the constant power field weakening region are discussed. In the tests, the load torque is always in the same direction, that is, with positive rotor speed demands the load is opposing the motion, whereas regeneration occurs when the torque and speed have different signs. The results show the proposed schemes performance compared to the classical open-loop $\mathrm{V} / \mathrm{Hz}$, an indirect rotor flux oriented vector control scheme, and the stator resistive voltage drop scheme [3].

\subsection{Start-up performance}

Fig. 2 shows rotor speed responses from 0 to $15.7 \mathrm{rad} / \mathrm{s}$ with no externally applied load (only frictional and inertial components of system) for the different schemes. This shows the problem described for [3] caused by $v_{s}=0$ when $\omega_{r}^{*}=0$. The faster responses produced by the $\mathrm{V} / \mathrm{Hz}$ and slip compensated methods are due to the boost voltage, and constant $v_{d s}^{e}$ term creating nominal stator flux linkage allowing quicker acceleration as no flux rise time is needed. Only $30 \mathrm{~ms}$ is needed for the slip compensated scheme compared to $70 \mathrm{~ms}$ for $\mathrm{V} / \mathrm{Hz}$ and $200 \mathrm{~ms}$ for the stator resistance voltage drop method, showing improvements of $57 \%$ and $85 \%$ respectively. For comparison, the vector control scheme takes $23 \mathrm{~ms}$ for full acceleration to occur. The proposed method shows a slope variation around 6.2 seconds. This is caused by a slight variation in $R_{S}$, the effects of which are discussed in Section 5. 


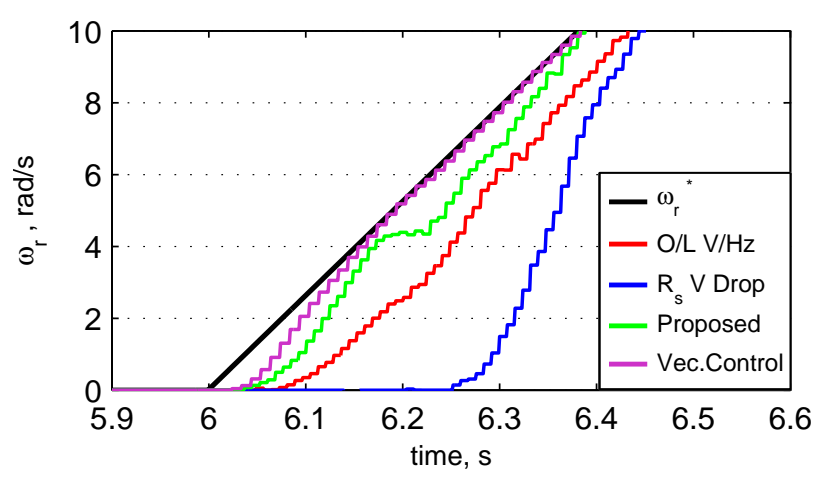

Fig. 2: Experimental start-up

\subsection{Dynamic behaviour}

To assess the torque disturbance rejection capabilities of the three scalar schemes Fig. 3 a shows responses to a $25 \%$ rated load torque impact when $\omega_{r}=15.7 \mathrm{rad} / \mathrm{s}$. This shows the superior performance of the slip compensated scheme. A steady state error of $0.16 \mathrm{rad} / \mathrm{s}(1.02 \%)$ is observed compared to $1.95 \mathrm{rad} / \mathrm{s}(12.4 \%)$ and $2.1 \mathrm{rad} / \mathrm{s}$ (13.4\%) for the $\mathrm{V} / \mathrm{Hz}$ and stator resistance voltage drop schemes respectively; a significant improvement in accuracy. Fig. 3 b compares the vector control and slip compensated schemes, the load induced speed drop is equivalent for both with recovery taking $120 \mathrm{~ms}$. A more oscillatory response is observed with the latter scheme. The response of the vector scheme is dependent on the speed loop PI tuning.

\subsection{Low $\omega_{r}^{*}$ stepped transient responses}

Experimental step test results from 15.7 to 0 and back to $15.7 \mathrm{rad} / \mathrm{s}$ for the scalar schemes are shown in Fig. 4a; showing both loaded low $\omega_{r}^{*}$ and $\omega_{r}^{*}=0$ operation is possible with the slip compensation holding $25 \%$ load at zero demand. The other schemes fail once $6.28 \mathrm{rad} / \mathrm{s}$ is reached. Loads up to $50 \%$ can be tolerated with the slip compensation down to $6.28 \mathrm{rad} / \mathrm{s}$, while $75 \%$ recovers with a rotor speed demand of $15.7 \mathrm{rad} / \mathrm{s}$ (Table 3). As $\omega_{r}$ is reduced these results show the effect of the noncompensated non-linearities consistent with using an inverter. Comparative responses for the vector and slip compensated methods are seen in Fig. 4b.

\subsection{Constant torque to constant power field weakening transition}

Fig. 5 shows responses to a 57.6 to $230.4 \mathrm{rad} / \mathrm{s}$ demand and the transition from the constant torque to the constant power field weakening region. The initial load impact shown at $57.6 \mathrm{rad} / \mathrm{s}$ equates to $25 \%$ rated, which becomes an equivalent of $50 \%$ once $230.4 \mathrm{rad} / \mathrm{s}$ is reached.
Compared to the $2.92 \mathrm{rad} / \mathrm{s}$ error for $\mathrm{V} / \mathrm{Hz}$ the slip compensation sees a significant improvement to $0.9 \mathrm{rad} / \mathrm{s}$ (68\% improvement). The method of [3] is not shown as there is no clear explanation of field weakening operation.
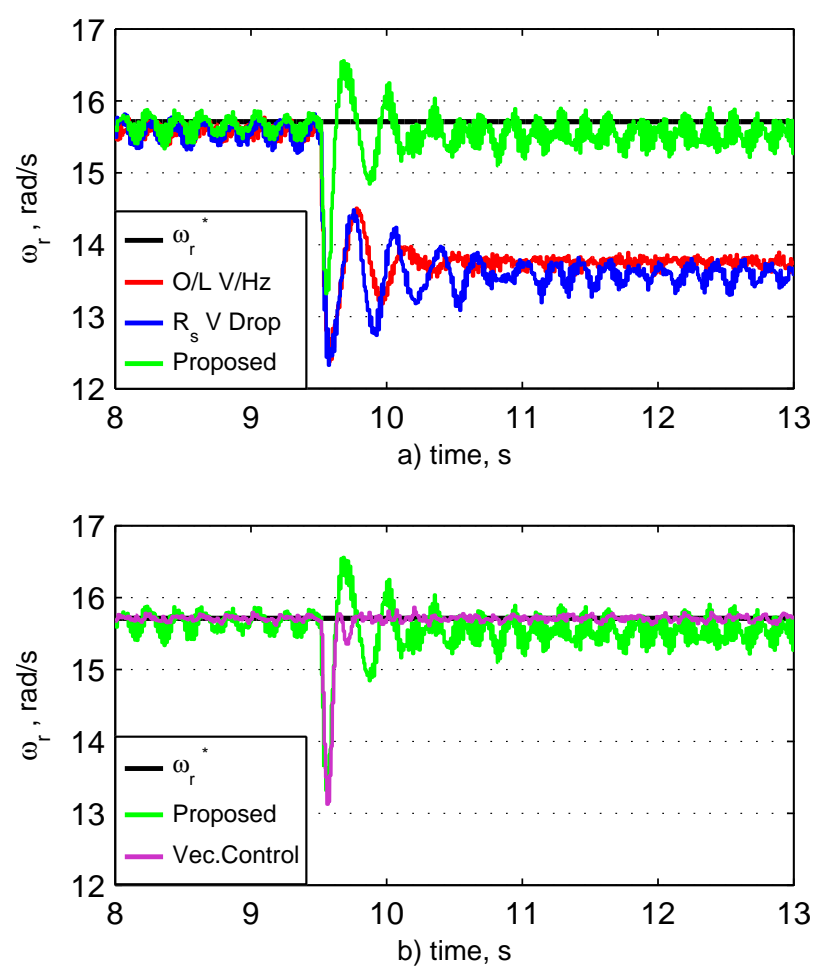

Fig. 3: Experimental 25\% load torque impacts at 15.7 $\mathrm{rad} / \mathrm{s}$, a) Scalar schemes, b) Proposed and vector control
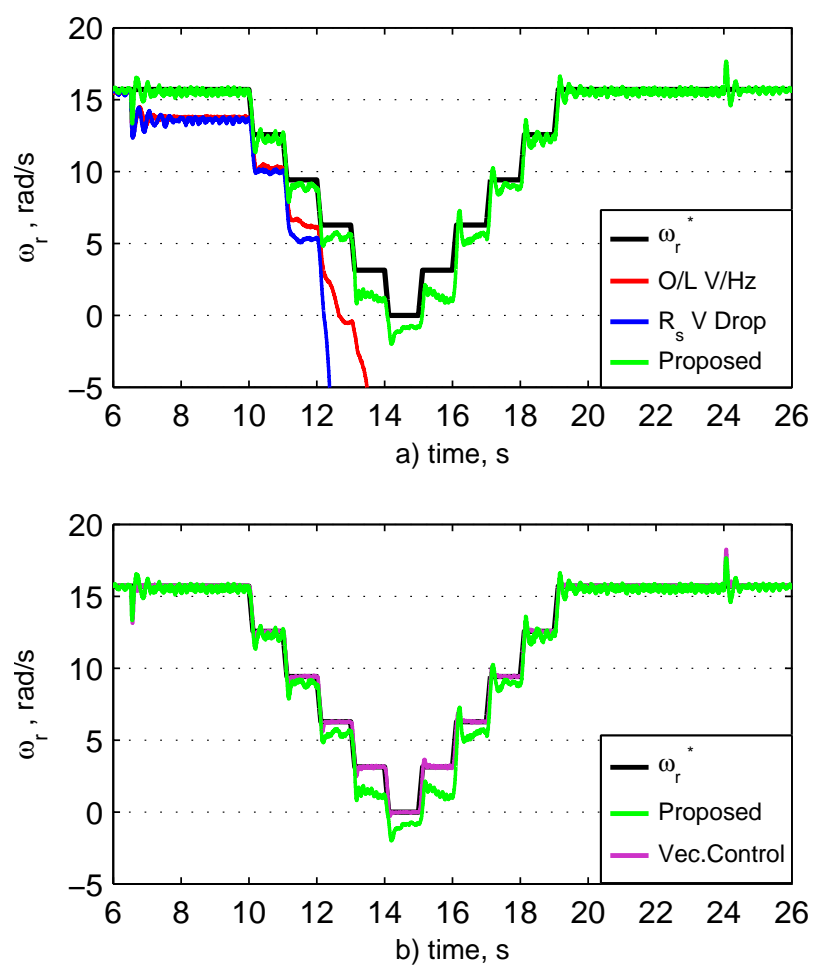

Fig. 4: 25\% load experimental step tests, a) Scalar schemes, b) Proposed and vector control 
As expected there is a reduction in the transient and zero steady state error seen with the encodered vector scheme. Fig. 6 shows a more thorough field weakening test of the proposed scheme. Unloaded acceleration to $125.6 \mathrm{rad} / \mathrm{s}$ is observed with rated torque applied and removed, followed by acceleration to $314 \mathrm{rad} / \mathrm{s}$ with a $20 \%$ load applied showing a $2.5 \%$ speed drop. The characteristic response of the rotor speed, electrical torque, stator current and stator fluxes are shown.

\subsection{Regenerative Capability \& Efficiency}

Fig. 7 shows the regenerative performance of the proposed scheme for a $25 \%$ load set of negative going stepped reference changes through zero speed. The negative speed values with positive torque $\left(i_{d s}^{e}, i_{q s}^{e}\right.$ positive) confirm this capability, but with a small effect on the orientation. Fig. 8 shows the electrical efficiency (neglecting mechanical losses) and power factor against load for the proposed scheme at $125.6 \mathrm{rad} / \mathrm{s}$. Linear slip frequency compensation might not correspond to lowest loss steady state operation, however, from the steady state results, $90 \%$ efficiency is achieved at $25 \%$ load reducing slightly as load increases, showing the effectiveness of the proposed scheme.

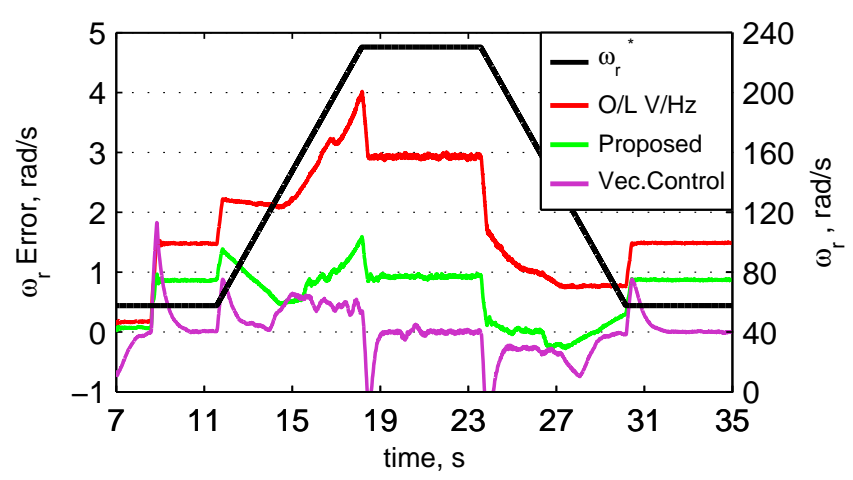

Fig. 5: Experimental constant torque to constant power operating region transition. $\omega_{r}$ error on left hand axis, $\omega_{r}^{*}$ on right hand side. $50 \%$ load in constant power region

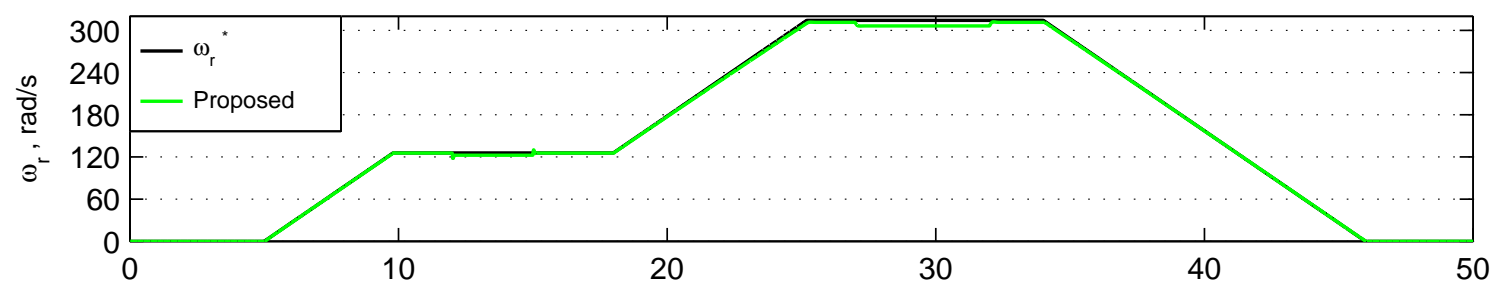

a) time, s

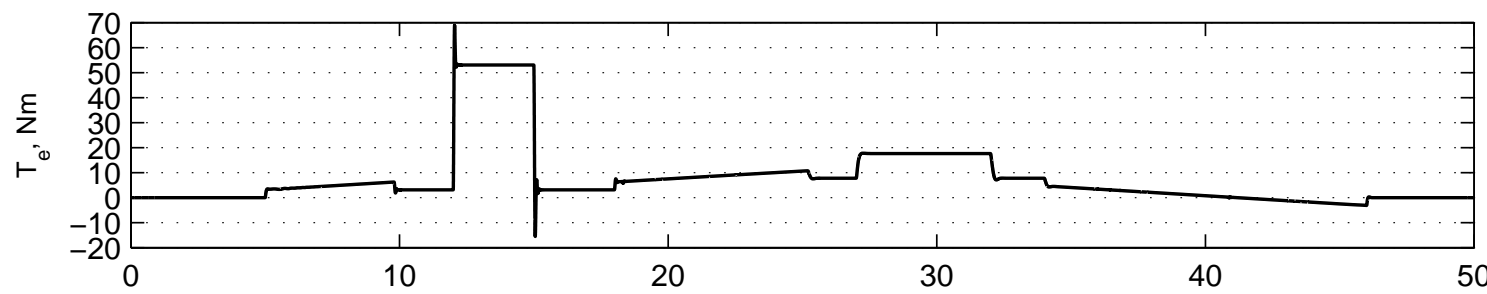

b) time, s

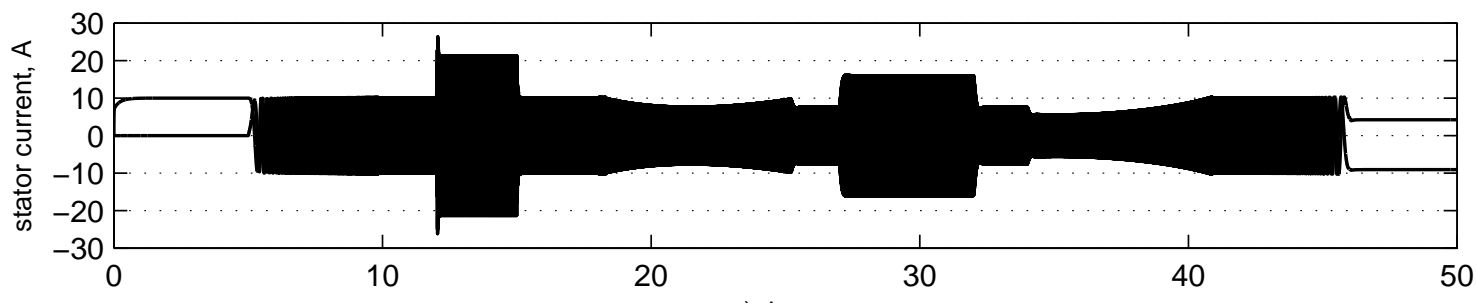

c) time, s

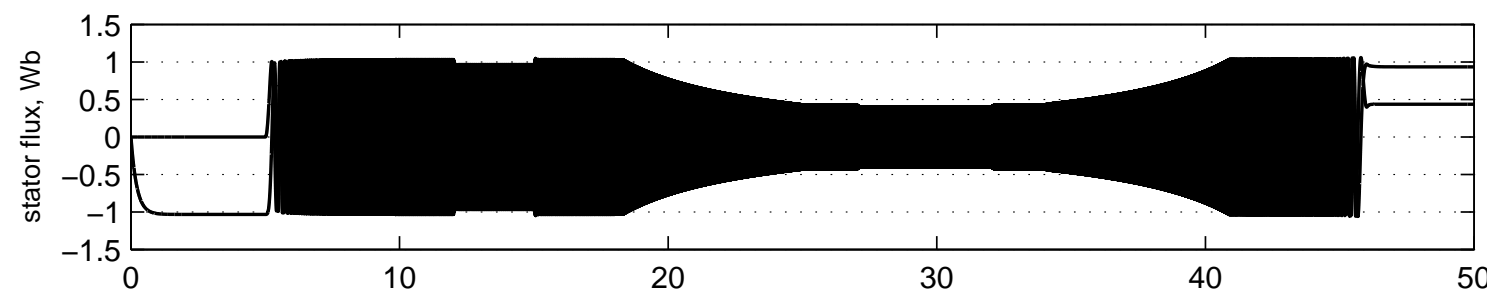

d) time, $s$

Fig. 6: Simulated responses of proposed scheme to 2.5 times rated speed with varying loads applied, a) $\omega_{r}$, b) Electrical torque, c) Stator currents, d) Stator flux 


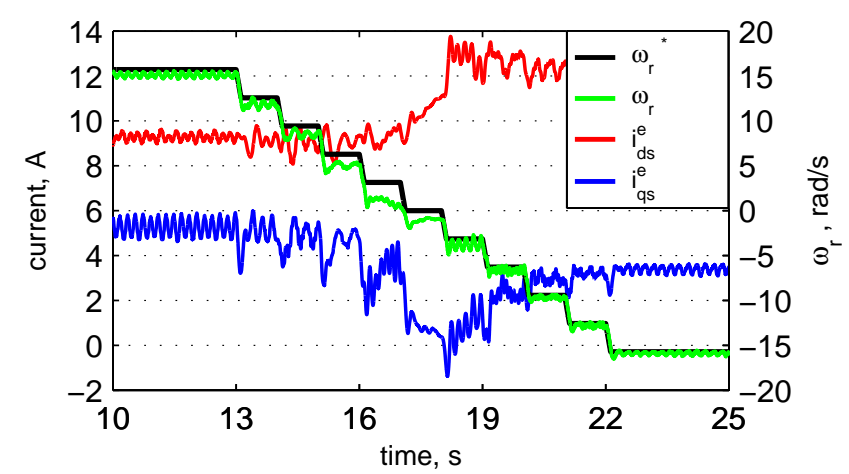

Fig. 7: Experimental 15.7 to $-15.7 \mathrm{rad} / \mathrm{s}$ step tests showing regenerative operation

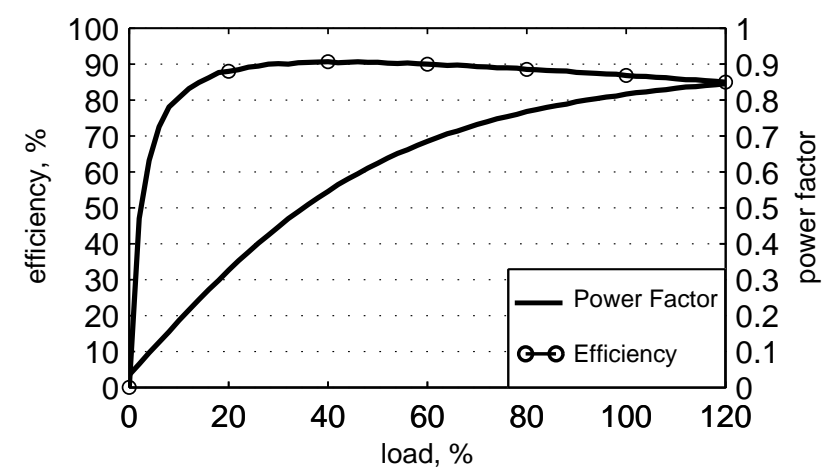

Fig. 8: Simulated electrical efficiency and power factor vs. load torque for proposed scheme at $125.6 \mathrm{rad} / \mathrm{s}$

\section{Effect of stator resistance variation}

Stator resistance variation has a large effect on the performance of control schemes. In [3] the stator resistance used $\left(\widetilde{R_{S}}\right)$ must be equal to or less than $0.8 R_{S}$, although [48] found inconsistencies within the stability analysis to obtain this value.

The effect of $R_{S}$ on the proposed scheme was analysed by altering the value used by $\pm 20 \%$ and $\pm 50 \%$. Low speed experimental results around and through zero speed showing regenerative operation for the $\pm 50 \%$ change are shown in Figs. 9a, 9b and 10a. As $R_{s}$ is altered, the $\omega_{r}$ responses are offset; this is caused by the slip compensation term. Fig. $10 \mathrm{~b}$ shows the simulated effect of a $\pm 20 \%$, and not $\pm 50 \%$, change in $R_{S}$ with load. In Figs. $9 \mathrm{~b}$ and $10 \mathrm{a}$, with the $\pm 50 \%$ change, failure occurs when approaching zero speed without recovery. The mechanism of this offset is explained as follows.

Figs. 11 and 12 show no load and loaded excitation frame currents $\left(i_{d s}^{e}, i_{q s}^{e}\right)$ for the results of Figs. 9 and 10, proving that $R_{S}$ variation alters not only the magnitude but more importantly the sign of $i_{q S}^{e}$. With no load the torque and hence slip are small in the steady state (only frictional terms) so limited $i_{q S}^{e}$ should be needed, for $R_{S}=R_{S_{-} n o m}$
$0.1 \mathrm{~A}$ is seen showing correct operation, this changes to $2.1 \mathrm{~A}$ and $-2.3 \mathrm{~A}$ for $R_{S}=0.5 R_{S_{-} \text {nom }} / R_{S}=1.5 R_{S_{-} \text {nom }}$, respectively. It should be noted that as $\omega_{r}$ reduces $i_{q s}^{e}$ goes slightly negative in Fig. 11a; this is the effect of the
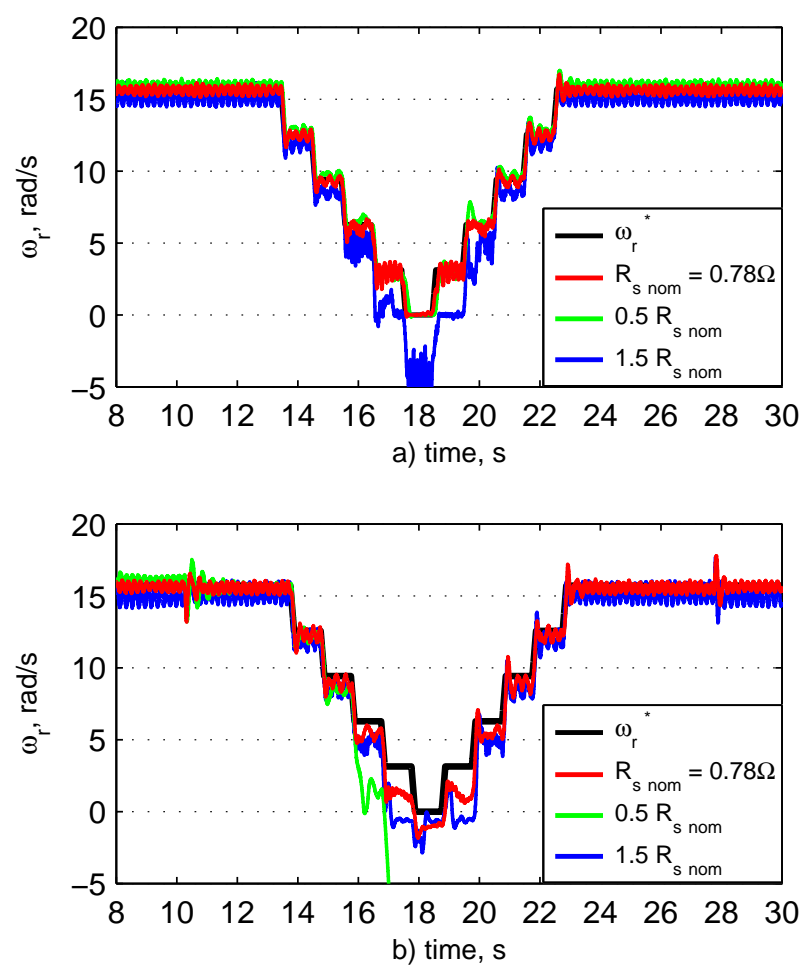

Fig. 9: Experimental 15.7 to 0 to $15.7 \mathrm{rad} / \mathrm{s}, 3.14 \mathrm{rad} / \mathrm{s}$ Steps, $\omega_{r}$ responses, a) No load, b) $25 \%$ load
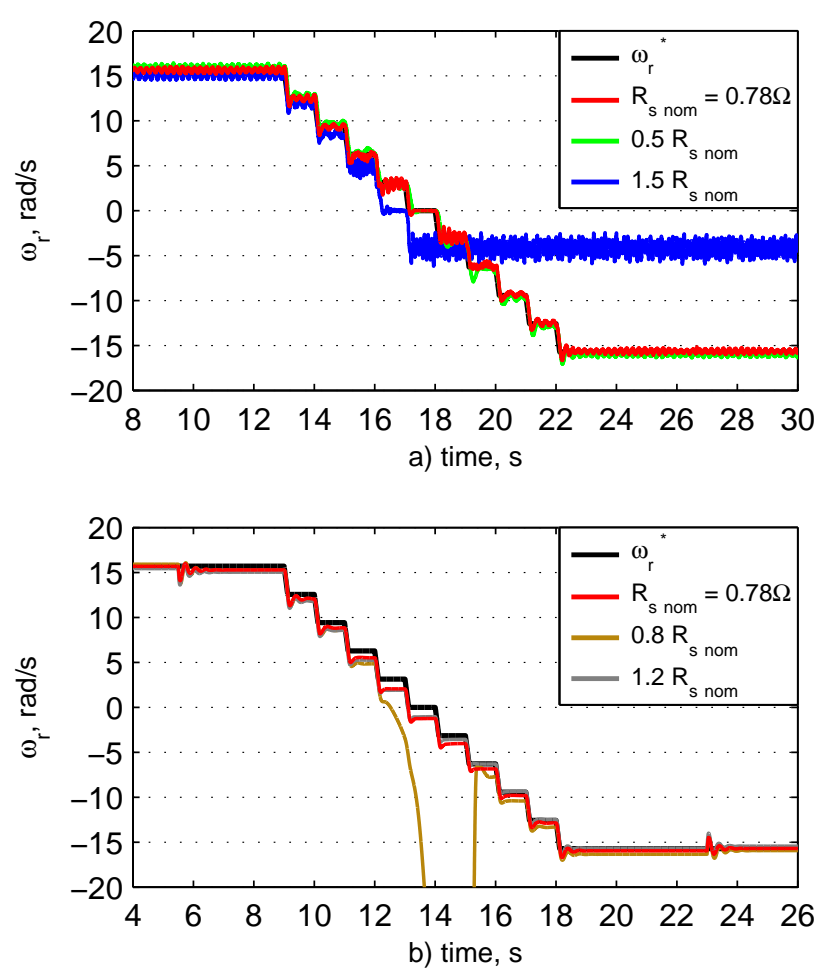

Fig. 10: From 15.7 to $-15.7 \mathrm{rad} / \mathrm{s}, 3.14 \mathrm{rad} / \mathrm{s}$ Steps, $\omega_{r}$ responses, a) Experimental no load, b) Simulated 25\% load 

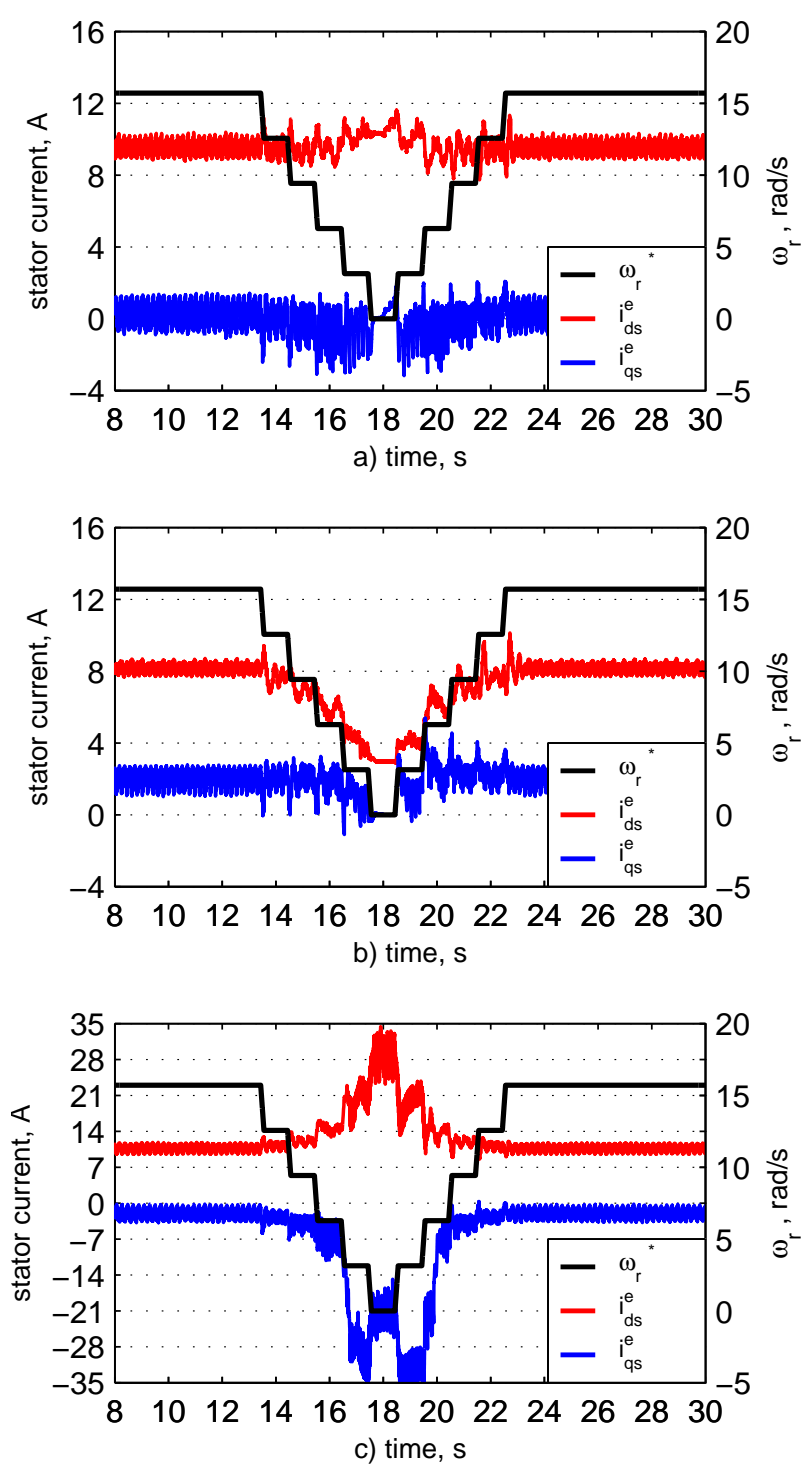

Fig. 11: Experimental 15.7 to 0 to $15.7 \mathrm{rad} / \mathrm{s}, 3.14 \mathrm{rad} / \mathrm{s}$ Steps, no load excitation frame Currents: a) $R_{s_{-} \text {nom }}$ b) $\left.0.5 R_{S_{-} n o m}, \mathrm{c}\right) 1.5 R_{S_{-} n o m},\left(\omega_{r}^{*}\right.$ shown for clarity $)$

$$
\begin{gathered}
Z_{e q}=\frac{v_{s}}{i_{s}}=R_{e q}+j X_{e q} \\
=R_{s}+X_{l s}+\frac{j X_{m}\left(\frac{R_{r}}{s}+j X_{l r}\right)}{\frac{R_{r}}{s}+j\left(X_{l r}+X_{m}\right)} \\
\phi=\tan ^{-1} \frac{X_{e q}}{R_{e q}}
\end{gathered}
$$

previously mentioned inverter non-linearities and the heating effect on $R_{S}$.

The $i_{q s}^{e}$ error is due to the magnitude of the demanded stator voltages $\left(v_{d s}^{e^{*}}, v_{q s}^{e^{*}}\right)$ and can be explained with phasor diagrams (Fig. 13). Figure 13a shows no load angles when $R_{s_{-} n o m}$ is used, the $\overline{i_{s}^{e}}$ angle compared to the $d$ axis is small giving a small $i_{q s}^{e}$ (as expected), this is because the $\overline{v_{s}^{e}}$ angle is similar to the stator voltage / current angle $(\phi)$ from the equivalent induction machine
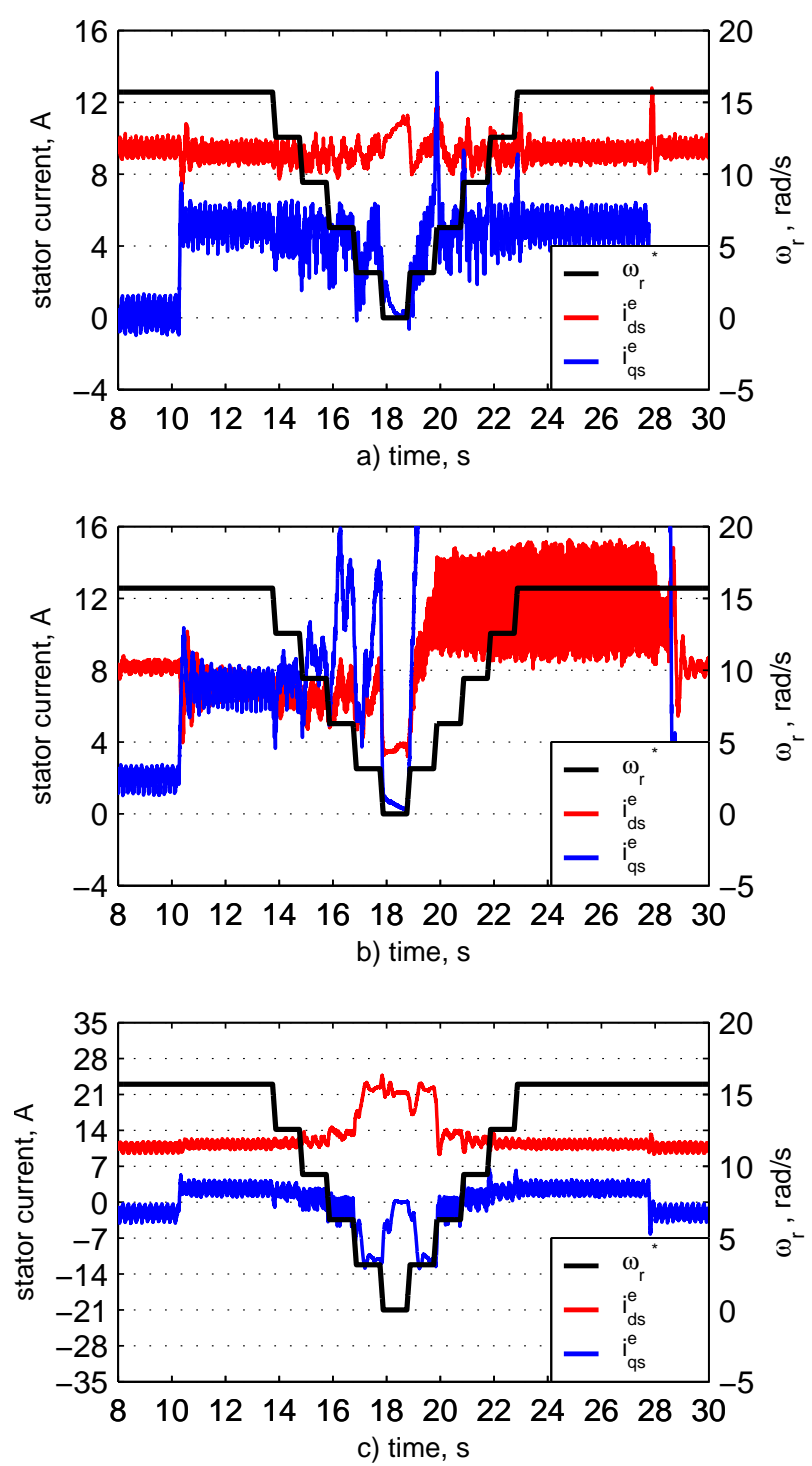

Fig. 12: Experimental 15.7 to 0 to $15.7 \mathrm{rad} / \mathrm{s}, 3.14 \mathrm{rad} / \mathrm{s}$ Steps, 25\% load excitation frame currents: a) $R_{S_{-} \text {nom }}$ b) $\left.0.5 R_{S_{-} n o m}, \mathrm{c}\right) 1.5 R_{S_{-}}$nom,$\left(\omega_{r}^{*}\right.$ shown for clarity)

impedance $\left(Z_{e q}\right),(24)$. As $R_{s}$ varies, the fixed $v_{d s}^{e}{ }^{*}$ term alters the angle of $\overline{v_{s}^{e}}$ compared to the $d$ axis; when $\phi$ is taken into account the $\overline{i_{s}^{e}}$ angle becomes $12.45^{\circ} /-12.61^{\circ}$ for $R_{S}=0.5 R_{S_{-} n o m} / R_{S}=1.5 R_{S_{-} n o m}$, respectively (Figs. $13 \mathrm{c} / 13 \mathrm{e})$. These incorrect angles and the $i_{q s}^{e}$ variations feed through the control system affecting the resistive compensation, but more importantly the slip compensation, either giving over or negative slip compensation. Hence $v_{d s}^{e}{ }^{*}$ is the dominant term for accuracy of this scheme. When loaded, the DC offset is greatly reduced as $i_{q s}^{e}$ becomes positive and the compensation terms work correctly (Figs. 13b/13d/13f), this is due to the load increasing the slip, altering $Z_{e q}$ and hence $\phi$. Owing to the initial errors the magnitudes of $i_{q s}^{e}$ are still different but due to the variation in $R_{S}$ the responses converge to a similar value, although $R_{S}=1.5 R_{S_{-} n o m}$ gives more 


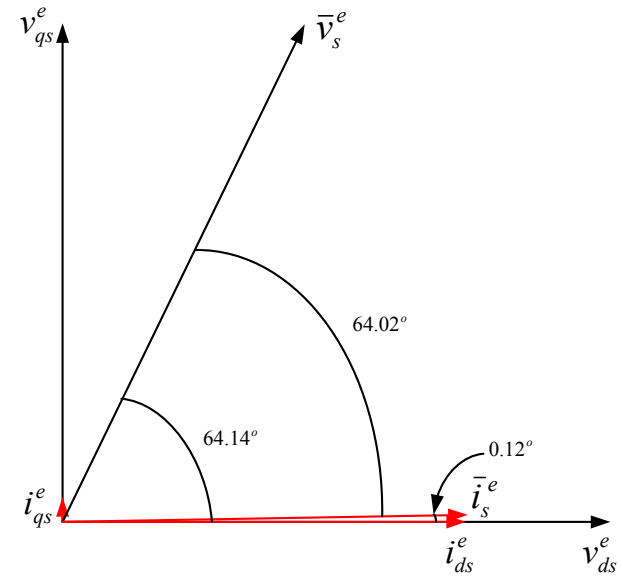

a) $R_{s}=R_{s_{-} \text {nom }}$, no load

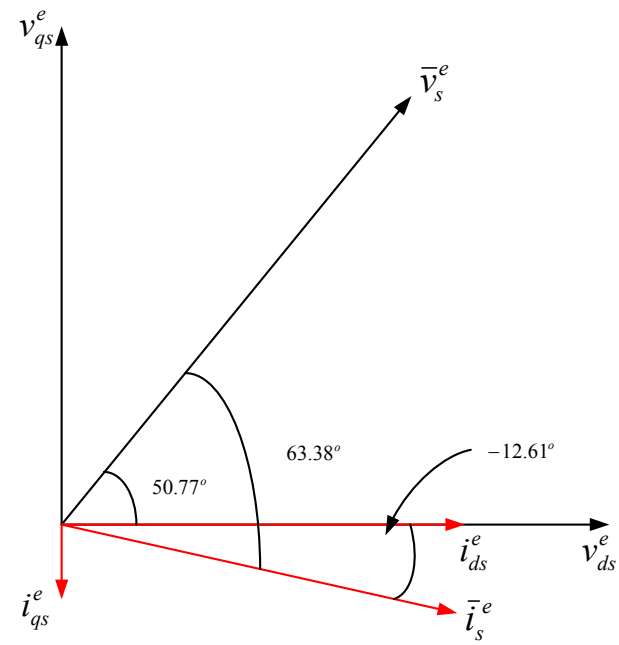

c) $R_{s}=1.5 R_{s_{-} \text {nom }}$, no load

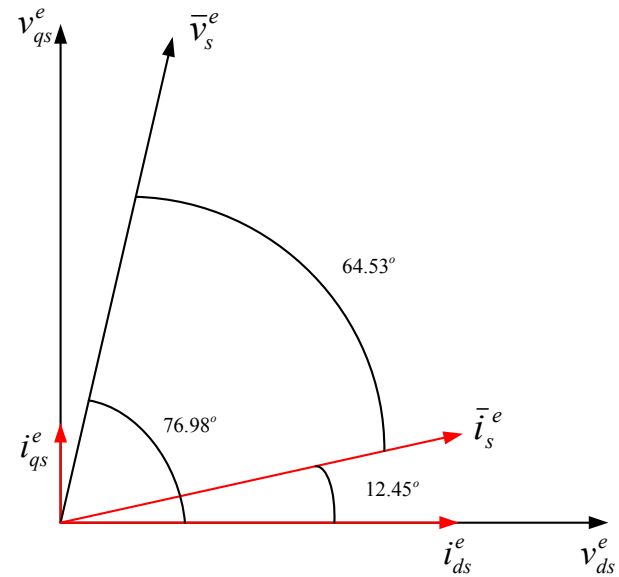

e) $R_{s}=0.5 R_{s \text { nom }}$, no load

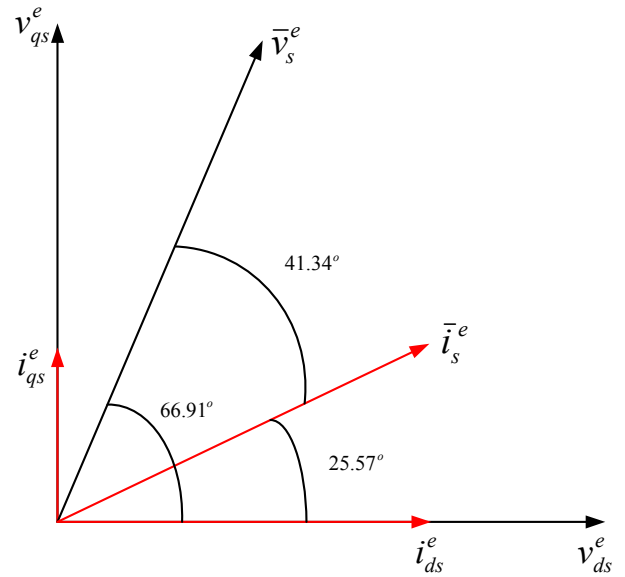

b) $R_{s}=R_{s_{-} \text {nom }}, 25 \%$ load

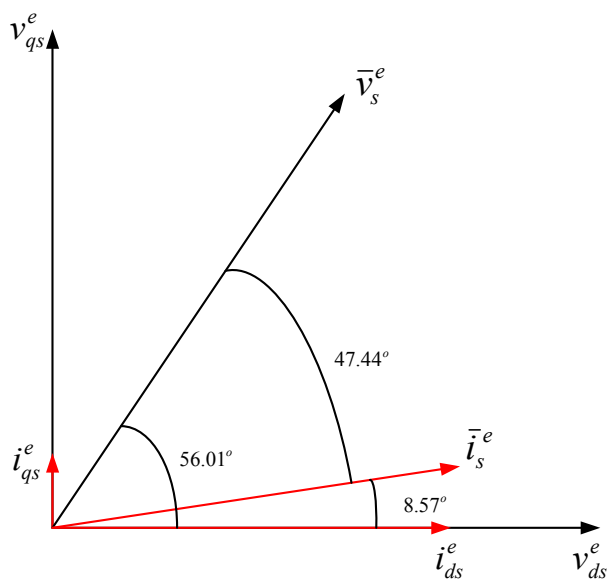

d) $R_{s}=1.5 R_{s_{-} \text {nom }}, 25 \%$ load

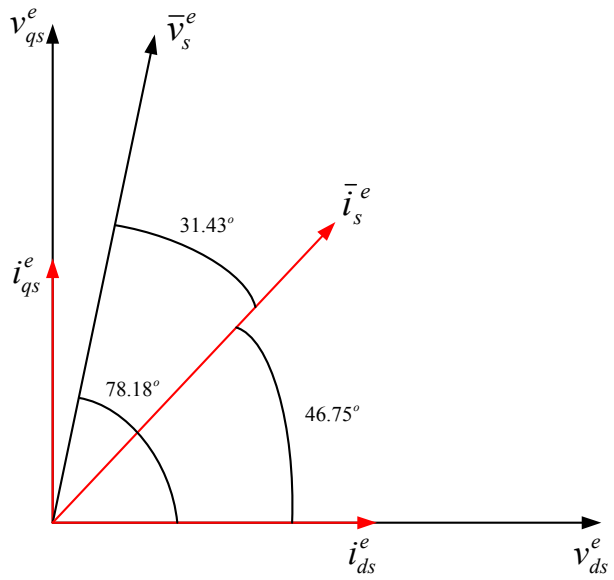

f) $R_{s}=0.5 R_{s_{-} \text {nom }}, 25 \%$ load

Fig. 13: Simulated excitation frame stator voltage / current magnitudes and angles at $15.7 \mathrm{rad} / \mathrm{s}$

oscillatory responses.

As with most scalar schemes, problematic operation occurs when lower values of $\omega_{r}$ are requested; loaded with $R_{S}<R_{S_{-} \text {nom }}$ failure occurs for the results shown due to the incomplete compensation of the voltage drop, and through the $d$-axis limited stator flux linkage being generated. For $R_{S}=1.5 R_{S_{-} \text {nom }}$ no load a negative speed is held and recovers for positive $\omega_{r}^{*}$, for regenerative operation it stays at $-4 \mathrm{rad} / \mathrm{s}$. Loaded, improved performance is achieved for positive $\omega_{r}^{*}$, but regenerative operation does not recover. A frequency fold back scheme is incorporated to limit the current 
and protect the drive, here it has reduced $\omega_{r}^{*}$ to zero but the incorrect $i_{q s}^{e}$ has a cumulative effect and the slip compensation loop controls the drive giving the results shown. Online $R_{S}$ estimation schemes, many of which have been discussed in the literature, could negate some of the issues seen. A full summary of the tests is provided in Tables 3-5, where ' $\checkmark$ ' means successful, ' $x$ ' failure, ' $\mathbf{R}$ ' recovers, and "Osc" is an oscillatory response. The $\%$ steady state errors are also shown for the load transients.

\section{Conclusion}

Scalar drives are not typically used for very high performance applications. However, in other less demanding applications their dynamic responses can still be acceptable. The open-loop slip compensated scalar scheme presented in this paper gives improved results during both steady state and transient conditions compared to other existing scalar methods. Importantly, both simulation and experimental results have shown superior responses for the proposed scheme at both low and high rotor speeds during motoring and generating operation. The effect of $R_{S}$ variation on the stability has been analysed during low speed operation (including regenerative operation), with a limitation of $R_{S_{-} \text {nom }} \leq$ $R_{s} \leq 1.2 R_{s_{-} \text {nom }}$, whereas the mechanism of the failures has been fully discussed. For higher speeds the effect of the variation on the performance is reduced.

This method does not completely match indirect rotor flux vector control, but has many advantages over other schemes presented despite the compromises used. The proposed method overcomes difficulties around and through zero speed, while a major improvement is achieved with the addition of slip compensation. This simple linear compensative terms complexity is significantly reduced compared to the non-linear versions, neglecting estimation of parameters such as the power factor and core loss. It is also much simpler than many previously discussed techniques involving estimation of the stator flux without any of the associated issues with integration such as offset and drift. Indirect rotor flux oriented vector control is dependent on accurate values of the inductance and $R_{r}$, which change with temperature and the operating speed range, so adaptation and characterisation are especially important, especially for the indirect slip calculation for orientation. This scheme only needs $R_{s}$, leading to a much reduced processing requirement.

Overall, the simple commissioning requirements, the removal of the need for an encoder or an estimation of the rotor speed, the overall compensating behaviour, and the small increase in the execution time from experimental testing compared to the other scalar schemes $(15 \%$ increase compared to $\mathrm{V} / \mathrm{Hz}, 4.5 \%$ to stator resistance voltage drop, $27 \%$ reduction compared to vector control) make it a potentially attractive control method for many industrial applications.

\section{Acknowledgements}

The authors wish to acknowledge support under the Engineering Doctoral Programme from EPSRC and Sevcon for this and related work.

Table 3: 15.7 to 0 to $15.7 \mathrm{rad} / \mathrm{s}, 3.14 \mathrm{rad} / \mathrm{s}$ Steps

\begin{tabular}{|c|c|c|c|c|c|c|c|c|c|}
\hline & \multicolumn{2}{|c|}{$\mathrm{O} / \mathrm{L} \mathrm{V} / \mathrm{Hz}$} & \multicolumn{2}{|c|}{$\begin{array}{c}\text { Stator resistance voltage } \\
\text { drop }\end{array}$} & \multicolumn{5}{|c|}{ Proposed } \\
\hline & No load & $25 \%$ load & No load & $25 \%$ load & No load & $25 \%$ load & $50 \%$ load & $75 \%$ load & $100 \%$ load \\
\hline$R_{s_{-} \text {nom }}$ & $\checkmark$ & $x$ & $\checkmark$ & $x$ & $\checkmark$ & $\checkmark$ & $x$ & $x$ & $x$ \\
\hline $0.8 R_{s_{-} \text {nom }}$ & & & $\checkmark$ & $x$ & $\checkmark$ & $x$ & $x$ & $x$ & $x$ \\
\hline $1.2 R_{S_{-} \text {nom }}$ & & & $\checkmark$ & $x$ & $\checkmark$ & $\checkmark$ & $\checkmark$ & $x$ & $x$ \\
\hline $0.5 R_{s_{-} \text {nom }}$ & & & $\checkmark$ & $x$ & $\checkmark$ & $x$ & $x$ & $x$ & $x$ \\
\hline $1.5 R_{S_{-} \text {nom }}$ & & & $\checkmark$, Osc & $x$ & $\mathrm{R}$ & $\checkmark$, Osc & $\checkmark$, Osc & $\mathrm{R}$ & $x$ \\
\hline
\end{tabular}


Table 4: 15.7 to $-15.7 \mathrm{rad} / \mathrm{s}, 3.14 \mathrm{rad} / \mathrm{s}$ Steps

\begin{tabular}{|c|c|c|c|c|c|c|c|c|}
\hline & \multicolumn{2}{|c|}{$\mathrm{O} / \mathrm{L} \mathrm{V} / \mathrm{Hz}$} & \multicolumn{2}{|c|}{$\begin{array}{l}\text { Stator resistance voltage } \\
\text { drop }\end{array}$} & \multicolumn{4}{|c|}{ Proposed } \\
\hline & No Load & $25 \%$ Load & No Load & $25 \%$ Load & No Load & $25 \%$ Load & $50 \%$ Load & $75 \%$ Load \\
\hline$R_{S_{-} \text {nom }}$ & $\checkmark$ & $x$ & $\checkmark$ & $x$ & $\checkmark$ & $\checkmark$ & $x$ & $x$ \\
\hline $0.8 R_{S_{-} \text {nom }}$ & & & $\checkmark$ & $x$ & $\checkmark$ & $x$ & $x$ & $x$ \\
\hline $1.2 R_{S_{-} \text {nom }}$ & & & $\checkmark$ & $x$ & $\checkmark$ & $\checkmark$ & $\checkmark$ & $x$ \\
\hline $0.5 R_{s_{-} \text {nom }}$ & & & $\checkmark$ & $x$ & $\checkmark$ & $x$ & $x$ & $x$ \\
\hline $1.5 R_{S_{\_} \text {nom }}$ & & & $\checkmark$, Osc & $x$ & $x$ & $x$ & $x$ & $x$ \\
\hline
\end{tabular}

Table 5: Load Torque impacts at $15.7 \mathrm{rad} / \mathrm{s}$

\begin{tabular}{|c|c|c|c|c|c|c|c|c|c|}
\hline & \multicolumn{2}{|c|}{$\mathrm{O} / \mathrm{L} \mathrm{V} / \mathrm{Hz}$} & \multicolumn{3}{|c|}{ Stator Resistance Voltage Drop } & \multicolumn{4}{|c|}{ Proposed } \\
\hline & $25 \%$ Load & $50 \%$ Load & $25 \%$ Load & $50 \%$ Load & $75 \%$ Load & $25 \%$ Load & $50 \%$ Load & $75 \%$ Load & $\begin{array}{l}100 \% \\
\text { Load }\end{array}$ \\
\hline$R_{S_{-} \text {nom }}$ & $\checkmark, 45.21 \%$ & $x$ & $\checkmark, 11.71 \%$ & $\checkmark, 38.54 \%$ & $x$ & $\checkmark, 1.13 \%$ & $\checkmark, 5.91 \%$ & $\checkmark, 20.23 \%$ & $x$ \\
\hline $0.8 R_{S_{-} \text {nom }}$ & & & $\checkmark, 12.49 \%$ & $\checkmark, 64.67 \%$ & $x$ & $\checkmark, 0.305 \%$ & $\checkmark, 7.05 \%$ & $x$ & $x$ \\
\hline $1.2 R_{S_{-} \text {nom }}$ & & & $\checkmark, 11.05 \%$ & $\checkmark, 31.18 \%$ & $x$ & $\checkmark, 2.15 \%$ & $\checkmark, 5.46 \%$ & $\checkmark, 13.36 \%$ & $\checkmark, 8.82 \%$ \\
\hline $0.5 R_{S_{-} \text {nom }}$ & & & $\checkmark, 13.93 \%$ & $x$ & $x$ & $\checkmark,-0.65 \%$ & $\checkmark, 11.51 \%$ & $x$ & $x$ \\
\hline $1.5 R_{S_{-} \text {nom }}$ & & & $\checkmark, 10.21 \%$ & $\checkmark, 25.22 \%$ & $\checkmark, 56.44 \%$ & $\checkmark, 3.99 \%$ & $\checkmark, 5.65 \%$ & $\checkmark, 9.28 \%$ & $\checkmark, 12.97 \%$ \\
\hline
\end{tabular}

\section{References}

[1] M. Suetake, I. N. da Silva, and A. Goedtel, "Embedded DSP-Based Compact Fuzzy System and Its Application for Induction-Motor V/f Speed Control," Industrial Electronics, IEEE Transactions on, vol. 58, pp. 750-760, 2011.

[2] T. H. Santos, A. Goedtel, S. A. O. Silva, and M. Suetake, "An ANN strategy applied to induction motor speed estimator in closed-loop scalar control," in Electrical Machines (ICEM), 2012 XXth International Conference on, 2012, pp. 844-850.

[3] C. J. Francis and H. Zelaya De La Parra, "Stator resistance voltage-drop compensation for open-loop AC drives," Electric Power Applications, IEE Proceedings -, vol. 144, pp. 21-26, 1997.

[4] L. Hui, W. Qingyi, D. Xin, and W. Shuyun, "A Novel V/f Scalar Controlled Induction Motor Drives with Compensation Based on Decoupled Stator Current," in Industrial Technology, 2006. ICIT 2006. IEEE International Conference on, 2006, pp. 1989-1994.

[5] C. Lascu, I. Boldea, and F. Blaabjerg, "Direct torque control of sensorless induction motor drives: a slidingmode approach," Industry Applications, IEEE

Transactions on, vol. 40, pp. 582-590, 2004.

[6] I. Boldea, "Control issues in adjustable speed drives," Industrial Electronics Magazine, IEEE, vol. 2, pp. 3250, 2008.

[7] B. Drury, Control Techniques Drives and Controls Handbook (2nd Edition): Institution of Engineering and Technology, 2009.

[8] W. Drury, "Industrial drives - A view of the future," in Electrical Machines and Power Electronics, 2007.
ACEMP '07. International Aegean Conference on, 2007, pp. 1-8.

[9] R. W. De Doncker, "Modern Electrical Drives: Design and Future Trends," in Power Electronics and Motion Control Conference, 2006. IPEMC 2006. CES/IEEE 5th International, 2006, pp. 1-8.

[10] V. T. Buyukdegirmenci and P. T. Krein, "Control for high instantaneous torque from induction machines: Methods and limits," in Electric Machines \& Drives Conference (IEMDC), 2011 IEEE International, 2011, pp. 777-782.

[11] H. Rehman and X. Longya, "Alternative Energy Vehicles Drive System: Control, Flux and Torque Estimation, and Efficiency Optimization," Vehicular Technology, IEEE Transactions on, vol. 60, pp. 3625 3634, 2011.

[12] J. Holtz, "Sensorless Control of Induction Machines With or Without Signal Injection?," Industrial Electronics, IEEE Transactions on, vol. 53, pp. 7-30, 2006.

[13] J. W. Finch and D. Giaouris, "Controlled AC Electrical Drives," Industrial Electronics, IEEE Transactions on, vol. 55, pp. 481-491, 2008.

[14] S. Bolognani, L. Peretti, and M. Zigliotto, "Parameter Sensitivity Analysis of an Improved Open-Loop Speed Estimate for Induction Motor Drives," Power Electronics, IEEE Transactions on, vol. 23, pp. 21272135, 2008

[15] H. A. Toliyat, M. Wlas, and Z. Krzemiriski, "NeuralNetwork-Based Parameter Estimations of Induction Motors," Industrial Electronics, IEEE Transactions on, vol. 55, pp. 1783-1794, 2008.

[16] G. Kenne, R. S. Simo, F. Lamnabhi-Lagarrigue, A. Arzande, and J. C. Vannier, "An Online Simplified 
Rotor Resistance Estimator for Induction Motors," Control Systems Technology, IEEE Transactions on, vol. 18, pp. 1188-1194, 2010.

[17] M. Barut, R. Demir, E. Zerdali, and R. Inan, "RealTime Implementation of Bi Input-Extended Kalman Filter-Based Estimator for Speed-Sensorless Control of Induction Motors," Industrial Electronics, IEEE Transactions on, vol. 59, pp. 4197-4206, 2012.

[18] A. Munoz-Garcia, T. A. Lipo, and D. W. Novotny, "A new induction motor V/f control method capable of high-performance regulation at low speeds," Industry Applications, IEEE Transactions on, vol. 34, pp. 813821, 1998.

[19] A. T. de Almeida, F. J. T. E. Ferreira, and D. Both, "Technical and economical considerations in the application of variable-speed drives with electric motor systems," Industry Applications, IEEE Transactions on, vol. 41, pp. 188-199, 2005.

[20] F. J. T. E. Ferreira, J. A. C. Fong, and A. T. de Almeida, "Ecoanalysis of Variable-Speed Drives for Flow Regulation in Pumping Systems," Industrial Electronics, IEEE Transactions on, vol. 58, pp. 2117-2125, 2011.

[21] D. Diallo, M. E. H. Benbouzid, and A. Makouf, "A fault-tolerant control architecture for induction motor drives in automotive applications," Vehicular Technology, IEEE Transactions on, vol. 53, pp. 1847$1855,2004$.

[22] A. Oteafy and J. Chiasson, "A Study of the Lyapunov Stability of an Open-Loop Induction Machine," Control Systems Technology, IEEE Transactions on, vol. 18, pp. 1469-1476, 2010.

[23] A. Sayed-Ahmed and N. A. O. Demerdash, "FaultTolerant Operation of Delta-Connected Scalar- and Vector-Controlled AC Motor Drives," Power Electronics, IEEE Transactions on, vol. 27, pp. 30413049, 2012.

[24] A. Consoli, G. Scarcella, G. Scelba, and M. Cacciato, "Energy efficient sensorless scalar control for full speed operating range IM drives," in Power Electronics and Applications (EPE 2011), Proceedings of the 2011-14th European Conference on, 2011, pp. 1-10.

[25] C. T. Ltd, Unidrive SP Advanced User Guide vol. Issue 10, 2011.

[26] J. Pongpant, S. Po-ngam, and M. Konghirun, "The Performance Improvement of Constant V/f Control of Induction Motor Drive in Low Speed Range," in TENCON 2006. 2006 IEEE Region 10 Conference, 2006, pp. 1-4.

[27] J. Sun, W. Zheng, and Z. Hou, "One novel scalar control scheme for induction machine," in Industrial Electronics Society, 2004. IECON 2004. 30th Annual Conference of IEEE, 2004, pp. 347-352 Vol. 1.

[28] Y. Rongfeng, C. Wei, Y. Yong, and X. Dianguo, "A novel V/F control system based on stator voltage oriented method," in Electrical Machines and Systems, 2008. ICEMS 2008. International Conference on, 2008, pp. 83-87.

[29] J. Pongpant and S. Po-ngam, "Open-Loop Torque Boost and Simple Slip Frequency Compensation for General Propose V/f Inverters," presented at the 2th International Conference on Electrical Engineering/Electronics, Computer, Telecommunications and Information Technology (ECTI-CON 2005), 2005.

[30] I. I. Incze, M. Imecs, and C. Szabo, "Enhanced VoltageFrequency Control Method for Induction Motor," in Intelligent Engineering Systems, 2004. INES '04. Proceedings. 2004 IEEE International Conference on, Cluj-Napoca, Romania, 2004, pp. 387-392.
[31] M. Tsuji, Z. Xiaodan, Z. He, S. I. Hamasaki, and C. Shuo, "Steady-state and transient characteristics of a novel V/f controlled induction motor," in Electrical Machines and Systems, 2009. ICEMS 2009. International Conference on, 2009, pp. 1-6.

[32] N. P. Rubin, R. G. Harley, and G. Diana, "Evaluation of various slip estimation techniques for an induction machine operating under field-oriented control conditions," Industry Applications, IEEE Transactions on, vol. 28, pp. 1367-1375, 1992.

[33] M. Orman, M. Orkisz, and C. T. Pinto, "Slip estimation of a large induction machine based on MCSA," in Diagnostics for Electric Machines, Power Electronics \& Drives (SDEMPED), 2011 IEEE International Symposium on, 2011, pp. 568-572.

[34] M. Abul Masrur, R. J. Hampo, and J. M. Miller, "Rotational sensorless scalar control of three-phase induction motors and its application to automotive electric power assist steering," Proceedings of the Institution of Mechanical Engineers Part D Journal of automobile engineering, vol. 214 Part D, pp. 33-44, 2000.

[35] Y. Binying, M. Cirrincione, G. Cirrincione, M. Pucci, and G. Vitale, "Improved sensorless scalar control by a PLL tracking rotor slotting effects," in Sensorless Control for Electrical Drives (SLED), 2012 IEEE Symposium on, 2012, pp. 1-5.

[36] C. J. Francis, H. Z. de la Parra, and K. W. E. Cheng, "Practical implementation of a stator flux oriented control scheme for an induction machine," in Power Electronics and Variable-Speed Drives, 1994. Fifth International Conference on, 1994, pp. 54-59.

[37] L. Yong, H. Wenxin, and H. Yuwen, "A Low Cost Implementation of Stator-Flux-Oriented Induction Motor Drive," in Electrical Machines and Systems, 2005. ICEMS 2005. Proceedings of the Eighth International Conference on, 2005, pp. 1534-1538.

[38] Y. Xue, X. Xu, T. G. Habetler, and D. M. Divan, "A stator flux-oriented voltage source variable-speed drive based on DC link measurement," Industry Applications, IEEE Transactions on, vol. 27, pp. 962-969, 1991.

[39] W. Chun-Chieh and F. Chih-Hsing, "Sensorless scalarcontrolled induction motor drives with modified flux observer," Energy Conversion, IEEE Transactions on, vol. 18, pp. 181-186, 2003.

[40] K. Koga, R. Ueda, and T. Sonoda, "Constitution of V/f control for reducing the steady-state speed error to zero in induction motor drive system," Industry Applications, IEEE Transactions on, vol. 28, pp. 463-471, 1992.

[41] M. Tsuji, Z. Xiaodan, Z. He, and S. Hamasaki, "A new simplified V/f control of induction motor for precise speed operation," in Electrical Machines and Systems (ICEMS), 2011 International Conference on, 2011, pp. $1-6$.

[42] H. Jun and W. Bin, "New integration algorithms for estimating motor flux over a wide speed range," Power Electronics, IEEE Transactions on, vol. 13, pp. 969-977, 1998.

[43] G. Mirzaeva and R. E. Betz, "Natural Field Orientation Concept: a Tutorial," in Electric Machines \& Drives Conference, 2007. IEMDC '07. IEEE International, 2007, pp. 1276-1281.

[44] R. E. Betz and G. Mirzaeva, "Frame Alignment Stability Issues in Natural Field Orientation," Industry Applications, IEEE Transactions on, vol. 44, pp. 575593, 2008.

[45] R. Ancuti, I. Boldea, and G. D. Andreescu, "Sensorless V/f control of high-speed surface permanent magnet synchronous motor drives with two novel stabilising 
loops for fast dynamics and robustness," Electric Power Applications, IET, vol. 4, pp. 149-157, 2010.

[46] A. Moldovan, S. C. Agarlita, G. D. Andreescu, and I. Boldea, "Wide speed range V/f with stabilizing loops control of tooth-wound IPMSM drives," in Optimization of Electrical and Electronic Equipment (OPTIM), 2012 13th International Conference on, 2012, pp. 424-431.

[47] K. Ohyama, G. M. Asher, and M. Sumner,

"Comparative analysis of experimental performance and stability of sensorless induction motor drives," Industrial Electronics, IEEE Transactions on, vol. 53, pp. 178-186, 2006.

[48] D. Giaouris and J. W. Finch, "Open Loop Control for AC Drives," presented at the 4th International Conference on Technology and Automation, Thessaloniki, Greece, 2002. 